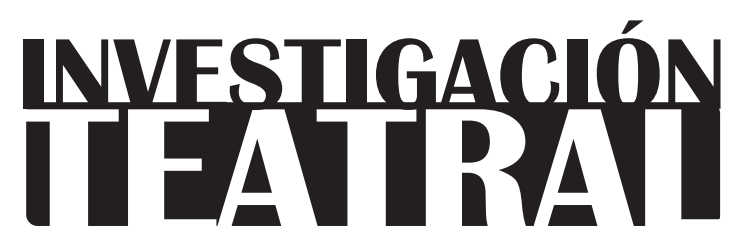

Revista de artes escénicas y performatividad

Vol. 12, Núm. 19

abril-septiembre 2021

Segunda época

ISSN impreso: $1665-8728$

ISSN electrónico: 2594-0953

Universidad Veracruzana

\title{
Angélica Liddell: autonomía de la palabra y pensamiento trágico contemporáneo
}

Fernanda del Monte Martínez*

\footnotetext{
* Instituto de Estudios Críticos, México. e-mail: teatro@17edu.org
}

Recibido: 05 de agosto de 2020

Aceptado: 26 de enero de 2021

Doi: $10.25009 /$ it.v12i19.2662 


\title{
Angélica Liddell: autonomía de la palabra y pensamiento trágico contemporáneo
}

\section{Resumen}

Este artículo aborda el libro Trilogía del infinito, de la creadora española Angélica Liddell, para indagar de qué forma sus textos poéticos ejercen una escritura performativa que entreteje temas filosóficos y estéticos como son la verdad, la belleza, el horror y lo trágico. Se analiza de qué forma la propuesta escritural de Liddell se aparta de los cánones dramáticos y se presenta como texto autónomo de la puesta en escena.

Palabras clave: Performatividad; anagnórisis; escritura performativa; exceso; desubjetivización.

\section{Angélica Liddell: The Written Word's Autonomyand Contemporary Tragic Thought}

\begin{abstract}
Spanish author and theatre director, Angélica Liddell's latest publication is Trilogía del infinito (Trilogy of the Infinite, 2016), a performative text in which she addresses philosophical and aesthetic issues such as truth, beauty, horror and tragic thought. This article discusses how Liddell's book breaks with dramatic canons and exists as an autonomous text which may be later staged in a performative mode.
\end{abstract}

Keywords: Performativity; anagnorisis; performative writing; excess; mystisism; de-subjectivization.. 


\section{Angélica Liddell: autonomía de la palabra y pensamiento trágico contemporáneo}

\section{Presentación}

a más reciente publicación de la creadora española Angélica Liddell -Trilogía del infinito- es una obra que posiciona a la autora como una de las poetas y performers más potentes de la lengua hispanoamericana de las primeras dos décadas del actual siglo. El trabajo de Liddell abreva de los místicos españoles, de los escritores barrocos y de los poetas hispanos, tomando de esta tradición una reflexión teológica y filosófica sobre el problema de la belleza y la verdad. El libro y los textos ahí reunidos no son de fácil acceso porque el lenguaje está en otra esfera de referencia, trabajado a partir de estructuras escriturales flotantes. Se trata de una escritura de lo inmanente, de una subjetividad absoluta que juega con la autoficción, y por lo tanto, crea un mundo onírico velado que, al mismo tiempo, parece tocar las fibras de una verdad reflejo.

Podría hacer un análisis de la obra a partir la relación entre las puestas en escena que Angélica Liddell ha realizado en las últimas décadas y su trabajo literario, pero me parece que lo que intenta con esta nueva publicación es, justamente, salirse de los bordes de la escena para ampliar y expandir las posibilidades de la palabra y el lenguaje, y por lo tanto del pensamiento, relación con la escena y la escritura literaria. Trilogía del infinito es una reunión de textos que se desbordan de la escena para convertirse en un textualidad performativa. ${ }^{1}$

1 Con textualidad performativa me refiero a trabajos literarios que se construyen a partir de una diversidad de textos que se sostienen como propuesta escritural autónoma que performa o acciona en los bordes de la escritura corpórea, no solo como textos para ser montados escénicamente. 
Trilogía del infinito es un compendio, la suma de varios textos escritos a priori y a posteriori de ser utilizados de distintas formas en los performances de la autora. ${ }^{2}$ Se trata de una edición que, dentro de sus páginas, contiene una escritura autorreferencial donde su verdad poética se muestra libre y autónoma. Liddell es una artista que ya ha dado cuenta de su energía en el escenario, pero que con este material logra trasladar la podredumbre que, en ocasiones, expone frente al espectador a la sutileza de una exégesis del lenguaje poético.

\section{Trilogía del infinito y el concepto de sacrificio poético}

Para analizar Trilogía del infinito de Angélica Liddell debemos entrar en el ámbito del lenguaje, por un lado, y de lo inconmensurable del mismo, por otro. El objetivo de estos textos es, como está escrito en la propia publicación, sobre la belleza, su ausencia y delirio: "He vuelto al problema de la Belleza" (Trilogía del infinito 126), escribe la autora. Dicho problema está relacionado desde el marco de estudio aquí presentado con los rasgos de lo trágico en la escena teatral contemporánea y también desde el punto de vista estructural con la idea de la imposibilidad de la representación.

Liddell es conocida por sus trabajos de teatro contemporáneo ( $E l$ año de Ricardo, La casa de la fuerza, Premio Nacional de Literatura 2012, entre muchos otros), en los que se aprecia una propuesta performativa y un cruce con el lenguaje poético. Sus obras son montajes de imágenes y signos donde el drama da paso a una teatralidad inmediata, ya no mediada por la representación, sino expuesta de frente al espectador a partir de acciones directas sobre el cuerpo. En las páginas que siguen indago sobre la escritura de Angélica Liddell más que en su trabajo escénico porque, a partir de la crisis de la representación, la autora ha encontrado en la escritura no teatral el umbral de nuevos campos.

En Trilogía del infinito, Liddell trabaja con su lengua madre, para acceder a lo que no se puede representar miméticamente: lo divino, lo demoniaco, lo violento, lo pagano y lo místico, pertenecientes al ámbito de lo fantasmático. La compilación de textos crea una mitología personal a la que nunca miramos de frente. Lo que está ahí permanece en las sombras y aun así es capaz de configurar un mundo místico. Para lograrlo, crea un panteón de mitos, cadáveres y fantasmas.

Joseph Campbell nos dice que la mitología "[...] hace que la actitud trágica aparezca hasta cierto punto histórica y el juicio meramente moral limitado" (49). Los interlocutores

2 Algunos de los textos reunidos en Trilogía del infinito forman parte de las siguientes puestas en escena de la autora: Esta breve tragedia de la carne, estrenada en 2015, en el Festival La Bâtie de Ginebra; ¿Qué haré yo con esa espada?, Teatros de la Canal, España 2018, y Génesis vi, Teatros de la Canal, Madrid, 2018. 
de Liddell son los asesinos, los caníbales y los santos, con quienes se encuentra a partir del principio de lo trágico. Como asegura Eduardo Grüner: "La tragedia tiene aquí un lugar de pasaje, en su mismo centro está el conflicto arcaico entre lo mismo y lo otro, que apunta a una separación y al (re) inicio de un nuevo orden" (El fin 308).

En este sentido, lo trágico se centra en volver a la pregunta fundacional de la polis. Escribe Liddell:

Miro los lugares desde los que saltaría al vacío y eso hace que mi cuerpo huela a sangre. Tu llegada hace que mi cuerpo huela a sangre. El origen de la tragedia es el mismo origen de la vida, el enigma, tu vida es un enigma, le dice Tiresias a Edipo, es aquello que nos hace caminar sin descanso hacia la muerte (Trilogía del infinito 71).

Es a partir de este origen trágico que ella encuentra el espacio de escritura y su interlocutor. En el libro se presenta una serie de textos amorfos que van desde un diario a un poemario. También nos encontramos con una especie de relato mítico sobre ser poseído, o sobre lograr la "iluminación” a partir de la caída. En el texto “¿Qué haré yo con esa espada?", ubicado en la primera parte del libro, Liddell transcribe un diario en el que observa la monstruosidad alrededor suyo en sus trayectos de Tokio a París. Es una especie de preparación para la poesía, donde el cuerpo duele: "Mi cuerpo empeora, los eczemas de los brazos y las piernas se han inflamado, ya no sé cómo calmar la comezón, el prurito que me recuerda la idea de castigo" (Trilogía del infinito 70).

Esa enfermedad del cuerpo le permite entrar al espacio de lo sagrado donde su interlocutor es lo divino. Pero este ámbito de lo divino también lacera, también provoca la enfermedad y la locura. Mediante su escritura, Liddell va entrando hacia círculos más profundos del ser. Ya no se trata de solo el dolor corporal, sino que parece que la vida se sostiene sin ser deseada. Pero ella no se vuelve víctima de eso que le duele, sino que se vuelve, igual que los monstruos que la rodean, la victimaria poética de los otros.

Heme aquí, junto al perro que yo más amo,

El amor es la respuesta

al profundo afán de significado que tiene el hombre.

Los perros lo rubrican.

Llegados a cierto punto tendré que cortarle la garganta,

si transcurridos quince segundos

todavía le queda un resto de vida

si todavía le queda un resto de preciosa vida

hundiré el cuchillo en sus entrañas 
abriéndome espacio en su interior con el puño, la sangre manchará la punta de tus zapatos y sus tripas se enredarán en tus tobillos (139).

Su enemigo es el hombre, su escritura está ahí contra él (y ella). Esto le provoca una nostalgia por la belleza tan profunda que la lleva a desear la muerte de otros, y la de ella misma. A partir de la escritura, Liddell teje un mundo alrededor de aproximaciones diversas para acceder a la belleza, quebranta entonces lo racional y se apoya en una escritura con el cuerpo que se vuelve el receptáculo a partir del cual acceder a esa belleza. Hay que exceder al cuerpo, sacrificarlo para acceder a la belleza. Esto es lo que ella denomina el sacrificio como acto poético. Aquí encontramos una relación entre lo corpóreo, lo excesivo del sentir y el desborde poético que es limítrofe con la perversión y el sacrificio trágico. La nostalgia por la belleza nos lleva al sacrificio como acto poético, algo que la Trilogía del infinito nos presenta casi sin que nos demos cuenta, con cada verso del libro.

Esta deformidad de los textos y el sinsentido que generan provocan una creación de sentido poético y de abismo al que uno como lector tiene acceso, a la caída de la escritura, del ser y de su imposibilidad de dejar ser humano, en este caso el acceso a lo perverso y monstruoso. Es esta dislocación de mirada que permite también encontrarse con lo divino, sin tocarlo, sin representarlo, sin convertirlo en imagen, sin hacerlo "drama".

Esta particular forma de acercamiento a temas filosóficos convierte a Trilogía del infinito en una escritura de lo trágico porque expone esa tensión desviada, en primera instancia subjetiva y al mismo tiempo trascendental. En estos textos, como en las tragedias, parece que hay un destino marcado por dioses con los que habla "Angélica", personaje creado a partir de su propia voz en un juego de autoficción y sacrificado poético. A lo largo de párrafos enteros del libro, vemos a una Angélica que pide que la hieran, que la violen, que la maten, porque ella ya está poseída, no puede seguir viviendo.

Si en el drama clásico los temas se trataban de forma directa, encarnada en personajes ficcionales, en el teatro contemporáneo eso ha pasado a la creación de acciones performativas (ver Féral). En este caso, Liddell da un paso más allá y deja el escenario para volcarse a la escritura amorfa y diegética de la dramaturgia contemporánea que posibilita volver a tocar ciertos temas relacionados con el pensamiento trágico de forma más afectiva.

Con su escritura, la autora hace acto matérico su concepto sobre el sacrificio de lo poético. Ella es el chivo sacrificado que se convierte en poesía. Aquí es donde podemos decir que la de Liddell es una escritura performativa (aspecto que desarrollaremos más adelante), que la vuelve escenario de su propia expiación. La escritura está sin duda relacionada estéticamente con su trabajo teatral en el que se realiza una escena corporal que expone el 
sufrimiento desde lo presencial del mismo, por ejemplo, cruzado entre la palabra y la sangre, los orines o la mierda que han sido elementos performativos de muchos de sus montajes. ${ }^{3}$ En las obras de Liddell se registra un acto performativo del dolor que genera expiación, no de las culpas sino de la existencia. Todos estos rasgos ponen a Trilogía del infinito en el roce constante del pensamiento de lo trágico con "la experiencia velada del terror. [...] La estetización vela el terror de la transgresión” (Lehmann, Tragedia y teatro 82).

Liddell expone en su ensayo "Abraham y el sacrificio dramático":

El sacrificio es un asesinato en suspenso, está por tanto por encima de la ética. El sacrifico poético es transgresión pura. Esto significa, como ya dijimos antes, enfrentarse a la sociedad, a una serie de circunstancias históricas, políticas, sociales y familiares que nos definen, y por tanto, en el sacrificio poético se produce un enfrentamiento a las normas y el resultado es lo INCOMPRESIBLE, pero solo mediante lo INCOMPREN$\operatorname{SIBLE}^{4}$ de la transgresión puede alcanzar una nueva reconfiguración del mundo $(E l$ sacrificio 112).

Estos son conceptos que vemos materializados en la escritura de la Trilogía del infinito. El concepto se vuelve escritura; la escritura, acto matérico de eso que se busca: el autosacrificio poético. Este sacrificio poético se instala entonces como un rasgo de lo trágico en la escritura contemporánea que permite la performatividad, la poesía y la autorreferencialidad.

Dentro de lo trágico existen dos nociones que se desprenden de las figuras de Edipo y Antígona. Sin duda, aunque no sea una postura expuesta en la escritura de Liddell, hay una visión radical que configura una femineidad de lo trágico relacionada con Antígona, como aquella que es capaz de exceder la vida y la ley para cumplir con cierto "deber ser" interior. Christoph Menke desarrolla la reflexión sobre figuras míticas hechas tragedia por los griegos, centrándose en Edipo:

Para garantizar la relación entre yo y nosotros, en muchos contextos en los que se presentan errores existe alguien, (un maestro o un árbitro), que habla en nombre de todos y con ellos en nombre del modo de actuación practicado en cada caso y de sus normas propias. Justo porque es necesaria esta instancia para los grandes errores de Edipo, la objetividad del juicio sobre el error se muestra aquí con especial claridad: Edipo puede juzgar él mismo sus acciones; no necesita ningún juez como representante autorizado

3 Desde su montaje emblemático de La casa de la fuerza podemos ver que las escenas realizadas por Liddell son "reales" y juegan con la creación de verdades poéticas.

4 Las mayúsculas son del texto original. 
de lo socialmente común, porque la evidencia aplastante con las que la descripción de sus acciones contiene una sentencia, asimismo, contienen la evidencia aplastante de que desde la perspectiva de todos nosotros deben ser juzgadas así. El yo que juzga sabe (pues para él es "absolutamente evidente") cómo juzgamos nosotros, cómo debe ser juzgado (108).

En este sentido, no es lo mismo mirar el destino trágico desde la figura de Antígona que desde la perspectiva de Edipo, el mismo rey y héroe trágico. En cambio Antígona está supeditada a la ley del otro. Desde el lugar de lo femenino en tanto lugar de enunciación, Angélica Liddell se pone en el lugar del personaje sacrificado. ¿Cómo lograr ser sacrificado sin ser la víctima? La respuesta se encuentra en los textos de Liddell, en su abordaje de lo monstruoso y exacerbado del cuerpo. La autora nos invita a conocer la podredumbre de un mundo donde lo moral se vuelve parte del paganismo primigenio. Este no es el lugar de Edipo (o de Hamlet) en la tragedia, es el lugar de Antígona, cuando ya está dentro de la cueva, en la soledad de los últimos días, en la soledad de la transgresión. Pero como Antígona, Liddell no es víctima porque ha cumplido su objetivo: tocar la belleza a través del sacrifico poético.

No entiendo lo que pasa, pues no hago lo que quiero, sino lo que aborrezco, Ahora bien, si hago lo que no quiero, estoy de acuerdo en que la ley es buena; pero en ese caso, ya no soy yo quien lo lleva a cabo sino el pecado que habita en mí. Yo sé que en mí, es decir, en mi naturaleza pecaminosa, nada bueno habita. Aunque deseo hacer lo bueno, no soy capaz de hacerlo.

De hecho, no hago el bien que quiero, sino el mal que no quiero. Y si hago lo que no quiero, ya no soy yo quien lo hace, sino el pecado que habita en mí. Así que descubro esta ley: que cuando quiero hacer el bien, me acompaña el mal. Porque en lo íntimo de mi ser me deleito en la ley de Dios; pero me doy cuenta de que en los miembros de mi cuerpo hay otra ley, que es la ley del pecado. Esta ley lucha contra la ley de mi mente, y me tiene cautivo.

¡Soy un pobre miserable! ¿Quién me librará de este cuerpo mortal? (Trilogía del infinito 202).

Otro de los rasgos de lo trágico en Trilogía del infinito se puede identificar en la connotación de Ley y Estado, en contraposición con la ley personal, la ética propia. Y en este sentido solo el sacrificio acciona y trastoca la ley. Tanto en el Abraham bíblico como en Antígona, el sacrificio trágico asume esta tensión, pero sobre todo la pone en duda. Expone el acto fundante de la polis y, por lo tanto, de la Ley del Estado, es decir: la sangre 
derramada por la imposición de la ley. Como argumenta Grüner, es en la tragedia que se desplaza la mirada y por lo tanto se subvierte la ecuación de contrato social, por lo tanto de la Ley como orden:

La insistencia en el ocultamiento de la decisión fundacional. Fundación del Otro como tal escamoteando el gesto de confesión de Parte con el Todo, función del Estado que desplaza la caótica violencia originaria detrás del acuerdo racional en el Contrato (Grüner, El fin 89).

La tragedia, y el pensamiento de lo trágico, logran poner frente al lector y espectador esta violencia que es parte y sustancia de la ley, y por lo tanto de lo humano. El sacrifico poético, en ese sentido, se configura como ese mecanismo estético que logra codificar en signos, ya sea de palabras o de expresión escénica y corporal, esa violencia inmanente para exponerla frente o "delante" de lo convenido entre ciudadanos. En un ejercicio de autoficción, escribe Liddell:

Es preferible no tener motivo alguno

para avalar nuestra existencia, que utilizar los motivos de la ley.

Porque no es la ley lo que necesita nuestro amor sino el horror.

El horror nuestro amor.

La razón es avaricia.

Y la pasión es generosidad.

Porque el hombre generoso no peca.

Aunque mate a su padre no peca.

Aunque fornique con su madre no peca.

Aunque descuartice a su mujer y a su amante no peca.

Porque la moral debe ser derrocada por sus actos

para que el alma exista

sobre las ruinas de un mundo legislado.

Pero mi ley es la antigua ley,

yo soy la dueña de las perras.

Qué pobre sería mi ley si dependiera de jurados, de jueces, de fiscales, de abogados.

Mi ley depende de la garganta de los gallos, y contra la razón sigo aullando (Trilogía del infinito 181). 
Las referencias del texto de Liddell son en primera instancia trágicas, tanto donde el texto apela a la ley del oikos subvertida de forma transgresora, como en los temas de lo propiamente trágico. Sabiendo que lo trágico toca los temas del sacrificio y la relación de la libertad con la ley de la ciudad, Liddell expone la ley como algo perteneciente al orden de lo avaro, de lo inmoral y de lo real-violento. Así podemos comprender el efecto catártico que logra la tragedia cuando sentimos temor y conmiseración con respecto al destino trágico de Edipo, o entendamos el destino de Antígona relacionado con la esfera de la moral que se opone a la ley de Creonte y del Estado. En sus escritos, la escritura poética de Liddell es una forma de encontrar la libertad y la belleza.

Como Antígona, Liddell apela a la ley de su propia existencia poética y no la de los jueces o jurados, sobre todo aludiendo a la corporalidad y la animalidad. En ese sentido, al arte de lo dionisiaco, concepto propuesto como origen de lo trágico desde la mirada de Nietzsche, está presente como poesía. En todos los textos del libro Trilogía del infinito, el desgarre de la carne se hace presente, convertido en poesía y palabras. Son las palabras las que se desgarran y destajan los conceptos del campo de lo racional y la ley de los hombres. Una y otra vez estas palabras supuran la moral. La autora se pone en el lugar de la prostituta, la asesina, la pecadora, con su fusil hecho de palabras, para dotar al espacio de lectura y de la escena de una libertad de ser y estar. Pareciera, a partir de estos textos, que la libertad hoy solo es posible en el extremo de romper con todo lo existente: el arte, la ley, la convivencia, la moral, el pensamiento, la lógica y la belleza apolínea.

En lo que se refiere al sacrificio poético, expone Liddell:

[E]n el tiempo de las muertes colectivas es necesario el sacrificio individual como rebeldía o barricada. El arte, sacrificio íntimo en un espacio público, es nuestra rebeldía. Gracias al sacrificio poético recuperamos la identidad que perdemos en la masacre. Somos animales que queremos decir yo. Porque animal no significa simplemente ser viviente. Ser viviente que pierde sus miembros por el aire junto a otra edición de miembros reventados. Con el sacrificio queremos decir yo. Por otra parte, gracias a la contemplación del sacrificio el espectador recupera la sensación de continuidad del yo (El sacrificio 99).

Así, este sacrificio poético se posiciona, al igual que la tragedia, en el espacio de la recuperación de la libertad a partir de la caída (del héroe trágico). Y es a partir de esta caída (o sacrificio) y la aceptación de un destino, que es posible recuperar cierta libertad de lo humano, pues en la aceptación de la caída viene la liberación, es decir en la acción ética que nos vuelve humanos. Lo humano está intrínsecamente relacionado con esa violencia fundacional, con la imposibilidad de huir de las luchas de los mismo y lo otro; por lo tanto, 
en esa idea de amor que aparece discursivamente en la escritura de Liddell, ese amor solo puede surgir desde la oscuridad y el horror que recuperan, que dan luz a esa relación animal, terrenal y, por ello, anterior a la imposición de la Ley.

Como expongo arriba, el amor y el sacrificio como acto poético están relacionados con la búsqueda de la belleza. Pero, para Liddell, la belleza se encuentra detrás de lo que parece bello; para llegar a ella hace falta derramar sangre, y dejar que el sujeto se desangre. Así, la autora materializa estéticamente el horror, nos permite a los lectores/ espectadores entrar en esa zona que nos es inaccesible (ya sea por falta de valor o de entendimiento), y que la escritura de Liddell, a partir de un acto de sacrificio poético personal, nos posibilita.

\section{Piedad y conmiseración como rasgos de lo trágico contemporáneo}

La estructura clásica de la tragedia en la dramaturgia contemporánea ha quedado fracturada y fragmentada a partir de la conversión del texto dramático en material para la escena, sobre todo en los espectáculos no dramáticos de creadores como Angélica Liddell y Romeo Castelucci. En su Trilogía del infinito, Liddell presenta textos-materia que se desprenden de la libertad que ha conferido la escena a la escritura con palabras. ${ }^{5} \mathrm{Si}$ asumimos lo que Lehmann plantea en su Teatro posdramático, donde a partir de la crisis de la representación se da la ruptura de dicha dialéctica entre escena y texto dramático, la escena teatral contemporánea propone una nueva relación no mimética y, por tanto, ha conferido autonomía a la escritura para teatro que ha llevado a algunos autores a revisitar la idea de escritura performativa más allá de un texto dramático canónico (creadores como Sarah Kane, Caryl Churchill, Emilio García Wehbi y Lola Arias). Estos autores, no obstante, encuentran en sus temáticas los referentes de la tradición teatral para insertarse en ella como nuevas textualidades dramatúrgicas. ${ }^{6}$

Así, el texto de Liddell está en un territorio literario y de escritura teatral que desborda los límites del drama, pero que no se inserta tampoco dentro de la clasificación de los géneros literarios. En Trilogía del infinito encontramos una relación de la escritura con los conceptos de piedad y conmiseración, presentes a lo largo de los textos fragmentados e inconexos del libro.

5 La escena teatral no dramática y de vanguardia posibilitan la escritura poética y la escritura desde una autonomía que no existe en la escritura dramática clásica que sigue reglas de acción, trama y estructura.

6 La relación entre textualidades contemporáneas y la escena denominada posdramática la explico a fondo en mi ensayo "Territorios textuales en el teatro denominado posdramático", (ver Del Monte). 
Algunos teóricos han ahondado en esta relación entre escritura verbal y la escena teatral contemporánea, entre los agrietamientos de dichas estructuras; entonces, es posible encontrarse de nuevo con el despliegue poético de ciertos temas de lo trágico, ahora desde otro lugar. Así encontramos que para Kernten Hausbi:

[...] aunque el drama ya no parece estar fundado sobre los poderes de la mímesis ni los de la catarsis y que no está relegado por el modelo del "bello animal" aristotélico, es afirmar lo evidente. Sin embargo, entre los materiales reciclados por la escritura teatral contemporánea es posible situar la presencia paradójica de elementos que provienen del proceso catártico: con toda seguridad el miedo, y quizás también, de manera reciente, la piedad (citado en Sarrazac 45).

Si nos adentramos a la propuesta catártica de Trilogía del infinito encontramos que, como afirma Hausbi, no se trata ya de generar terror, sino de escribir desde él. Lo catártico se vuelve así autorreferencial. La expiación es personal y está relacionada con el personaje autoficcional generado por Liddell para exponer su pensamiento poético. Este pensamiento está accionando no para definir una trama, sino más bien en un movimiento espacio-temporal. Como en los diarios de viaje, estos textos parecen venir de los momentos de relajación que tiene la artista entre un proyecto escénico y otro. Las palabras fluyen libremente sin el corset del aparato dramático, y así la escritura se vuelve un territorio de creación estética más cercana al pensamiento filosófico que al canon dramático.

El concepto del exceso es parte de esta nueva configuración textual. Es decir, la escritura no sólo está excedida en este trabajo literario, sino la forma desde donde parte esta escritura. Según Patrice Pavis, hay obras literarias en las que claramente se registra el exceso, ya que la literatura:

[...] igual que el teatro, tiene quizá la facultad, comprobada por poetas-filósofos como Artaud y Derrida, de empujar a la filosofía más allá de sus límites, e incluso sacarla de sus casillas y "exceder el concepto". [...] El exceso, la "parte maldita" (Bataille, 1967), es un gasto desperdiciado, que se manifiesta en la sexualidad liberada, el sacrificio, la exageración de toda vanguardia extremista, de todo juego que alcance el paroxismo. [...] El exceso, entonces, no es una simple forma de estilo, sino un procedimiento heurístico para señalar y figurar lo real en escena (126).

En su obra literaria, Liddell le da una vuelta más a la crisis de la representación para regresar a la epístola como forma de exceso, purgación y autosacrificio poético. Estos son los rasgos de lo trágico que posibilitan la catarsis dentro del texto y, en ese sentido, aludiendo a 
Aristóteles, devuelve la idea de catarsis, no ya como teoría de la recepción, sino como parte de las características de este héroe trágico que se nos presenta en la figura de la propia autora. Es ella quien se sacrifica y se deshace en vida con la propia escritura (o lo que nos hace creer a partir de la ficción poética). ¿Qué genera esto en el lector-espectador? Tendremos que asumir que este libro es un compendio de textos que se configuran como una estructura estética autónoma y que la "adaptación" de los mismos a la puesta en escena es otro mecanismo que se debe estudiar como objeto estético aparte. Estos textos exceden y dan cuenta de otra serie de pautas poéticas e indagaciones filosóficas que en las puestas en escena no vemos. La escena, como la misma Liddell enfatiza en entrevistas realizadas, ${ }^{7}$ tienen que ver con la búsqueda plástica de la escena, y estos textos entonces serán utilizados como escrituras no textocéntricas. ${ }^{8}$

Veremos que este mecanismo es usado, no sólo por Liddell, Kantor en su momento o García Wehbi, sino también en cómo conciben la dramaturgia contemporánea algunos creadores de nuestros días. El texto ya no es una obra dramática para ser montada, sino que es una posibilidad de exploración de lenguaje, un diario de dirección y de artista, un texto en prosa o poesía, una investigación o una exploración en tanto "libro"9 (ver Sarrazac). Ya en su texto “Teoría del Drama moderno", Peter Szondi avizoraba la relación no dialéctica entre algunas estructuras del drama moderno que podemos revisar en poéticas anteriores al siglo Xx. Textos barrocos como La vida es sueño de Calderón de la Barca dan la sensación de que no están escritos para la escena teatral, sino para su propia lectura. Muchos textos llamados dramáticos están excedidos de dicha estructura en su formas y su contenidos. Están desbordados en sus estructuras dramatúrgicas. No están escritos para ser llevados a escena como centro de una puesta en escena. En ese sentido, estaríamos hablando de una nueva dialéctica entre texto y escena donde de nuevo habría que encontrar o crear una relación entre escritura textual y escena teatral. Esta característica da una posibilidad distinta a la ficción y a la poesía, pero también a la tragedia.

Si George Steiner había hipotetizado (1956) con respecto a la muerte de la tragedia dentro de la estructura dramática y la desaparición del verso como forma ideal de la concreción de la tragedia en la escritura literaria, parecería que, en este nuevo siglo, la libertad del texto ha llevado a algunos artistas escénicos a explorar en la escritura no aristotélica y no dramática. Ellos ahora indagan en las paradojas de la representación (y de su imposibili-

7 Ver entrevista de Liddell en: https://www.youtube.com/watch?v=_wWVESM-40w.

8 Fundamento de lo posdramático.

9 Podemos encontrar ejemplos de este tipo de "materiales para la escena" en textos publicados por los creadores argentinos Emilio García Wehbi, Beatriz Catani, Lola Arias y Santiago Loza, quienes se afincan en la producción de textualidades no dramáticas para la escena teatral contemporánea. 
dad), así como en escrituras casi automáticas, intertextuales, surrealistas y místicos, como en el caso del libro Trilogía del infinito.

Los textos de Angélica Liddell están en el borde de un abismo. Tienen sus propios referentes, no hay muchos ganchos hacia el lector. Necesitamos de tiempo para poder entrar a ese universo donde el texto no lanza pistas claras de cuál sea el objetivo y hacia dónde nos quiere llevar. Tenemos ante nosotros fragmentos de cartas, diarios, epístolas y a una autora dialogando con un interlocutor que nunca aparece. Escritura en primera persona que después será dicha en escena por otros. ${ }^{10}$ Estos desfases nos descolocan, nos obligan a ir hacia otros espacios desde donde podemos releerla, verla, olerla y tratar de entenderla a partir también de lo emocional. El de Liddell es un libro que se "sufre". Nos escupe su autorreferencialidad desde la primera página y nos posiciona como intrusos ante un mundo donde se duele y se margina el espíritu. Ahí es donde encuentro que se asoman los conceptos de conmiseración y temor. No quisiéramos en ningún momento ser ella, ni estar en sus zapatos. Su posición desde la escritura con respecto al mundo es dolorosa, angustiosa y lacerante. La autora se lastima, se niega la alegría y se deshace en la búsqueda de una belleza inexistente.

Ella sabe que pierde y perderá, que no hay salida de este desconcierto de impureza e imperfección. Pero entonces, al igual que los héroes trágicos, no son ellos las víctimas, sino nosotros, con nuestra cotidianidad y vidas fútiles. Ella busca la belleza mientras nosotros miramos la realidad. En este sentido, la postura del "personaje" en primera persona de Liddell se relaciona con la idea nietzscheana de la voluntad y la búsqueda de la libertad que sabemos es imposible en un mundo contractual.

La conmiseración entonces no es para con ella, sino para con nosotros. Pero el intercambio de la miradas a partir de la postura del texto nos vuelve hacia la reflexión de nuestra propia existencia en reflejo a la suya. Un mecanismo, no de mímesis sino de diégesis, de distanciamiento, y es a partir de este rechazo del otro que nos podemos mirar de nuevo a nosotros desde una nueva perspectiva.

\section{Filosofía del discurso en la poética de Angélica Liddell}

Para comenzar a realizar un cruce entre pensamiento, pensamiento filosófico y pensamiento de lo trágico en el trabajo de Angélica Liddell, cito nuevamente a Patrice Pavis:

10 En sus montajes, Liddell hace decir a los performers que enuncian textos escritos por ella en primera persona. 
Sea cual sea el respeto que profesemos a la filosofía y a todo lo que ella aclara sobre la creación teatral, en la actualidad es necesario preguntarse si, a la inversa, no nos ayuda también la práctica teatral a realizar una nueva experiencia de la filosofía; si no pudiera acaso el trabajo de la escritura dramática o el trabajo escénico desembocar en alguna inesperada "iluminación" filosófica (138).

La pregunta de Pavis al momento de indagar en la relación entre filosofía y teatro, sin duda, nos permite abrir el abanico de análisis de la obra escritural tanto dede Liddell como de otros autores teatrales contemporáneos. Esta duda retórica abre la posibilidad de pensar en el teatro como parte de la creación de una filosofía del discurso, sobre todo a partir, como el mismo Pavis apunta una y otra vez, de dramaturgos-poetas-pensadores como Artaud y Derrida. ${ }^{11}$

Y pareciera que es el pensamiento trágico el más cercano a la creación o a la posición desde el pensamiento filosófico generado desde la escena o la escritura accionada o performativa, ya que es en el pensamiento trágico donde se da de manera más clara un posicionamiento dialéctico entre el ser humano y su sociedad. Es en el teatro donde las tensiones sociales, las tensiones entre individuos las tensiones entre individuos se materializan, ya sea de forma dramática o posdramática.

La idea de que las nuevas dramaturgias proponen una nueva mirada sobre el pensamiento trágico contemporáneo, sobre todo si tomamos en cuenta la forma y el contenido de La Trilogía del infinito, encontraremos que la pregunta principal que se produce a lo largo de las páginas es sobre la relación entre la belleza, la justicia, la sociedad y la libertad, temas vinculados con el pensamiento filosófico y político.

Las posibilidades de pensamiento crítico que nos pueden otorgar los textos de Angélica Liddell en relación al ámbito de lo social, las relaciones humanas, la relación entre individuo, ley y ética, son sin duda profundas y singulares. La posición donde se ubica su pensamiento desde lo poético desarticula los lugares comunes desde donde se piensa la escena, formal y simbólicamente. El texto de Liddell nos propone una nueva mirada sobre lo ético, lo político y lo filosófico. Es una escritora y creadora singular que se encuentra en un ámbito poético, por ello distanciado de la sociedad desde donde se la mira y se la juzga.

11 Antonin Artaud y Georges Bataille quizá sean dos de los escritores más importantes sobre la escritura de lo trágico. En su texto "Para terminar con el juicio de Dios", Artaud rompe con toda regla sintáctica para habitar las profundidades del "grito sacrificial": "Como no había más que tierra y bosque de huesos /tuvo que ganarse su alimento,/no había mierda/ sólo hierro y fuego,/y el hombre tuvo miedo de perder la mierda o más bien deseó la mierda /y para eso, sacrificó la sangre. Para tener mierda, es decir carne,/ donde sólo había sangre y chatarra de osamentas, donde no tenía nada que ganar y sí algo que perder: la vida. o reche modo /to edire/ de za/ tau dari/ do padera coco" (19). 
Para entender el pensamiento detrás de las palabras y creaciones de Liddell, habría que poner en claro que aquí no estamos hablando de textos presentacionales o discursivos, donde la voz de la autora es la que expone esos pensamientos, como en su libro de conferencias y artículos de El arte como sacrificio poético. Así, Trilogía del infinito nos enfrenta a un mundo ficcional de autorreferencialidad constante. A partir de este mundo representacional, no necesariamente dramático, es que se expone un mundo y un pensamiento que recoge las preocupaciones trágicas desde los inicios de los tiempos griegos. Si tomamos en cuenta la cita de Nietzsche en tanto qué sería el arte de lo dionisiaco y lo apolíneo, se lee:

Sobre todo se trataba de transformar aquellos pensamientos de náusea sobre lo espantoso y absurdo de la existencia en representaciones con las que se pueda vivir: esas representaciones son lo sublime, sometimiento artístico de lo espantoso, y lo ridículo, descarga de la náusea a lo absurdo (254).

Angélica Liddell parece sugerir que la cubre un velo, que lo que ve, escucha y siente está en un mundo intermedio, fronterizo entre lo real y la visión subjetiva y ficcional de esa realidad. Esto le permite crear su propio universo intermedio a partir del cual proferir pensamientos que se nos presentan como más verdaderos, por exacerbados. Para Nietzsche, el principio de subjetividad que plantea el poeta lírico es el que preserva con su expresión performativa aquellos rasgos del coro trágico, de los rituales paganos dirigidos al dios Dionisos y, por lo tanto, es él quien personifica la necesaria mirada subjetiva de la contemplación desinteresada que lo convierte en el verdadero poeta. El juego performativo de ser lo que se escribe y lo que se dice es, en definitiva, la característica tanto del poeta lírico como de la creadora Angélica Liddell.

El filósofo prusiano habla del principio dionisiaco como aquel que nos lleva a las raíces de lo ritual y lo excesivo, donde la relación entre verdad y arte se encuentran justamente en la desubjetivización que se logra a través del canto ditirambo. ${ }^{12}$ En la contemporaneidad esto no sucede de la misma manera, simplemente porque la identidad ya no es colectiva ni los valores compartidos. ¿Cómo se puede hablar de lo divino, o generar terror y conmiseración en un mundo basado en la perspectiva científica? Justamente yendo hacia lo inmanente: Dios.

Liddell realiza un mecanismo paradojal, donde, desde la mirada religiosa habla con Dios, con un otro, con el demonio, y donde las palabras pecado, santos, devoción se despliegan por todo el texto, que al igual que algunos escritos místicos de Santa Teresa o

12 Nietzsche plantea estos conceptos en el apartado "Visión dionisiaca del mundo", de su libro El origen de la tragedia. 
San Agustín, nos llevan al terreno de lo místico. El pensamiento filosófico en los textos de Liddell se encuentra en el campo fronterizo de lo pagano y lo sagrado. Y esta tensión y la forma en la que Liddell se posiciona desde la mirada sagrada sobre el mundo, la posiciona como pensadora, además de como poeta. Sin duda, hablar de verdad es entrar al mundo del pensamiento filosófico. Y parece que la tragedia es ese territorio que ha tocado de cerca o se ha preguntado sobre la verdad, la justicia y la relación de los hombres con lo divino. Por ello Christoph Menke, en su libro La actualidad de la tragedia, escribe:

Hablar de la "verdad" de esta experiencia trágica, en cambio, parece que significa convertir el arte (de la tragedia) en expresión de un conocimiento que también se puede formular con independencia de ella, es decir, convertir el arte (de la tragedia), en la expresión de una verdad filosófica. La elevación de la experiencia trágica a una experiencia "verdadera", repetiría entonces una vez más la "desemancipación" unida a todo discurso filosófico sobre la verdad, tanto descubierta como escondida en el arte (86).

Ya Nietzsche había hipotetizado con respecto a la idea de verdad en el arte, atribuyendo a la idea de símbolo y semblanza una posibilidad de verdad fuera del ámbito de la realidad. $\mathrm{Al}$ igual que Menke, dan posibilidad al pensamiento filosófico dentro del arte trágico, a través de un mecanismo distinto que el propuesto por la historia de la filosofía, o podríamos decir, a partir de un pensamiento lógico y argumental. Esta idea de que en el arte trágico pueda haber una verdad velada, escondida, o intuida, es lo que amplía la discusión entre verdad, filosofía y arte en general. En particular, desde el ámbito del pensamiento de lo trágico relacionado con los temas que siempre ha tratado la tragedia, encontramos que el trabajo en Trilogía del infinito, con el tema de la verdad, no solo se da como punto de partida, sino que se despliega como pensamiento expuesto a lo largo de todo el libro. El libro de Liddell "piensa" y, al hacerlo, encuentra ciertas verdades que están relacionadas con su pensamiento. A partir de una mirada particular y la poesía que el texto crea, la autora nos transmite su verdad personal, relacionada con una búsqueda imposible por la belleza emprendida por filósofos y poetas desde el principio de los tiempos.

\section{Fuentes consultadas}

Artaud, Antonin. Terminar con el juicio de Dios y otros poemas. Buenos Aires: Ediciones Caldén, 1975.

Campbell, Joseph. El héroe de las mil caras. Traducido por Luisa Josefina Hernández, México: Fondo de Cultura Económica, 1959. 
Del Monte, Fernanda. Territorios textuales en el denominado teatro posdramático. Ciudad de México: Paso de Gato, 2013.

Féral, Josette. "Por una poética de la performatividad: el teatro performativo". Investigación Teatral, vol. 6-7, núm. 10-11. 2017, pp. 25-50.

Grüner, Eduardo. La cosa política o el acecho de lo real. Buenos Aires: Espacios del Saber, Paidós, 2005.

Grüner, Eduardo. El fin de las pequeñas historias. Buenos Aires: Paidós, 2002.

Lehmann, Hans Thies. Tragedia y teatro dramático. Traducido por Claudia Cabrera. México: Paso de Gato. 2017.

Lehmann, Hans Thies. Teatro posdramático. Traducido por Claudia Cabrera. México: Paso de Gato, 2013.

Liddell, Angélica. El sacrificio como acto poético. Madrid: Con Tinta Me Tienes, 2015.

Liddell, Angélica. Entrevista. "Biennale Teatro 2016 - Meeting with Angélica Liddell”. YouTube, subido por 'BiennaleChannel', 9 agosto 2016, Teatro Piccolo Arsenale, https://www.youtube.com/watch?v=_wWVESM-40w, consultado en octubre de 2020.

Liddell, Angélica. Trilogía del infinito. Segovia: La uña rota, 2016.

Menke, Cristoph. La actualidad de la tragedia. Ensayo sobre juicio y representación. Madrid: La balsa de la Medusa, 2008.

Nietzsche, Friedrich. El origen de la tragedia. Barcelona: Editorial Alianza, 2013.

Pavis, Patrice. Diccionario de la performance y del teatro contemporáneo. México: Paso de Gato, 2016.

Sarrazac, Jean Pierre, coordinador. Léxico del drama moderno y contemporáneo. México: Paso de Gato, 2014.

Szondi, Peter. Teoría del Drama moderno, 1880-1956. Ed. Dykinson, Madrid. 2011. 